Doch zwei Monate nach Beginn der Behandlung beging er überraschend Selbstmord.

Eine 39-jährige Rückenschmerzpatientin hatte vor 20 Jahren depressive Phasen und einen Suizidversuch nach einem schlimmen Ereignis durchlebt. Zwei Monate nach dem Beginn der Behandlung mit Ziconotid berichtete sie über verstärkte Suizidgedanken, Halluzinationen, teilweisen Gedächtnisverlust und Verwirrtheit. In diesem Zeitraum war die Patientin in zwei schwere Autounfälle verwickelt. Daraufhin setzten die Mediziner die Ziconotidgabe aus. Die Suizidgedanken waren ebenso wie die anderen psychischen Symptome kurze Zeit später verschwunden.

Christoph Maier und seine Kollegen fordern, alle Patienten vor Behandlungsbeginn mit $\mathrm{Zi}$ - conotid sorgfältig auf psychische Störungen zu untersuchen. Auch während der Therapie sollte ihr psychischer Zustand engmaschig kontrolliert werden, unabhängig von einer Schmerzlinderung durch das Medikament.

Bei der Einführung von Ziconotid galt das synthetisch hergestellte Gift der Meeresschnecke Conus magus als sichere Alternative zu Morphin: Es verursacht keine Opioid-typischen Nebenwirkungen wie Atemdepression und die Patienten entwickeln keine Toleranz.

\section{Carina Jung}

Maier C, Gockel HH, Gruhn K et al. Increased risk of suicide under intrathecal ziconotide treatment? - a warning. PAIN online 1.11.2010; doi 10.1016/j.pain.2010.10.007.

\title{
Krebesentstehung
}

\section{Hunderte Mutationen in einer einzigen zellulären Katastrophe}

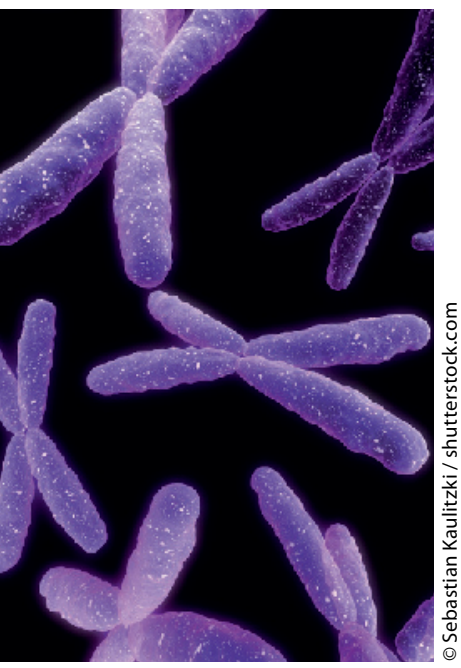

In einem zellulären Unfall können Teile von Chromosomen auseinandergerissen werden. Der DNA-Reparaturapparat versucht dann, sie wieder zusammenzufügen,

ist dabei jedoch oft überfordert - mit fatalen Folgen.
Ein Ereignis allein kann hunderte Mutationen auslösen und somit die Entartung einer Zelle weit vorantreiben. Vermutlich passiert dies bei 2-3\% aller Tumoren. Die Folgen des plötzlich auftretenden Geschehens, das ganze Chromosomenteile in Stücke reißen kann, zeigten Philip J. Stephens, Cambridge, Großbritannien, und Kollegen am Beispiel eines Patienten mit chronischer lymphatischer Leukämie (CLL). Im Gegensatz zu neun anderen untersuchten CLL-Patienten entdeckten sie bei ihm auffällige Muster in den DNA-Umlagerungen [Stephens PJ. Cell 2011; 144: 27-40]. Diese Umlagerungen unterschieden sich deutlich von den Veränderungen genomischer Instabilität wie sie bei Brust- Lungen oder Pankreastumoren beobachtet werden.

Bei genomischer Instabilität, durch die sich $\mathrm{Mu}$ tationen nach und nach akkumulieren, sind solche Rearrangements entweder über das ganze Genom verteilt oder - wenn sie sich auf bestimmte Bereiche beschränken - mit substanziellen genomischen Amplifikationen verbunden. Bei dem Patienten waren die Mutationen mit sehr geringen Amplifikationen auf wenige Chromosomenabschnitte beschränkt.

Weitere Analysen ergaben, dass die Mutationen im Genom des Patienten nicht nach und nach, sondern gleichzeitig entstanden sein müssen. „Konfrontiert mit hunderten von DNA-Brüchen versucht die DNA-Reparaturmaschinerie der Zelle das Genom zu retten. Das Resultat zeigt wenig Ähnlichkeit mit seiner ursprünglichen Struktur", so die Auto- ren. Mit diesen Erkenntnissen relativiert Stephens Arbeitsgruppe die aktuelle Ansicht, dass sich krebsauslösende Mutationen stets langsam über einen längeren Zeitraum ansammeln.

31 Monate nach der Entnahme der untersuchten Probe analysierten Stephens und Kollegen erneut das Tumorgenom und fanden keine neuen Rearrangements. Daraus schließen die Autoren, dass der Prozess, der zu den Umlagerungen geführt hatte, bereits vor der Erstdiagnose abgeschlossen war. Als Ursache erwägen sie ionisierende Strahlung, da diese die Doppelstrangbrüche verursachen kann oder Defekte in dem Mechanismus, der bei jeder Zellteilung ein Stück der Telomerenenden jedes Chromosoms entfernt.

Weitere Beispiele entdeckten Stephens und Kollegen, als sie sich die Genome von 20 Knochenkrebs-Patienten ansahen. Bei fünf von ihnen fanden sie ebenfalls analoge Muster $(25 \%$; $95 \%-\mathrm{KI} ; 10-49 \%)$. Außerdem ergab ein Vergleich der Genkopienzahl in den Profilen von 746 Krebszellinien in 18 Fällen Anzeichen von zellulären Krisen, die denen von Stephens Patienten entsprachen $(2,4 \%$; $95 \%$-KI; $1,5-3,9 \%)$. Sie kamen in vielen verschiedenen Tumorzellinien wie Lungenkrebs $(n=4)$, Gliomen $(n=3)$, Melanomen $(n=4)$ und kolorektalen Karzinomen $(\mathrm{n}=1)$ vor.

\section{Carina Jung}

Stephens PJ, Greenman CD, Fu, B. Massive Genomic Rearrangement Acquired in a Single Catastrophic Event during Cancer Development. Cell 2011;144:27-40.DOI 10.1016/j.cell.2010.11.055 